\title{
Desenvolvimento de um sistema de apoio a pacientes com zumbido
}

\author{
Ana Rita Nunes Ramos ${ }^{* *}$ (D) Gina Maria Vilão Ramos ${ }^{2}$, Maria Fernanda Gentil Costa ${ }^{3}$ (iD \\ 'Instituto Superior de Engenharia do Porto, Porto, Portugal; \\ ${ }^{2}$ Departamento de Física do Instituto Superior de Engenharia do Porto, Porto, Potugal; \\ ${ }^{3}$ Departamento de Audiologia da Escola Superior Saúde do Porto, Porto, Potugal. \\ * a ana.r.n.r@gmail.com
}

Recebido em: 31 maio 2020; Revisto em: 08 novembro 2020; Aceite em: 30 dezembro 2020

\begin{abstract}
Resumo
Introdução: O zumbido é um sintoma bastante perturbador, que se revela como uma sensação de "ouvir um som internamente". Existem várias teorias que tentam justificar o seu aparecimento, embora nem sempre concordantes. Há estudos que relacionam o aparecimento de zumbido com a perda auditiva, exposição ao ruído, stress e perturbação emocional, mas ainda serão necessárias mais estratégias de tratamento para esta população específica. Objetivos: Ao avaliar pacientes com zumbido, percebe-se que as maiores queixas se relacionam com o silêncio da noite, o que, consequentemente, perturba o ciclo circadiano. De forma a colmatar este problema, foi construído um dispositivo inserido numa almofada, passível de ser utilizado durante o adormecimento. A almofada funciona como forma terapêutica, mais concretamente como gerador sonoro. Materiais e Métodos: Foi desenvolvido um dispositivo eletrónico que permite reproduzir varias faixas sonoras, e posteriormente inserido numa almofada. Além disso, foram testados alguns materiais para preencher o seu interior, e de todos os que se mostraram mais eficazes foram a esponja e os caroços de cereja. Os estudos foram no sentido de avaliar a melhor solução em termos acústicos, na propagação da onda sonora no meio ambiente, mas também a melhor solução em termos de maior conforto para o paciente. Resultados: Foram obtidos resultados relativamente à propagação da onda sonora quando testada a almofada com esponja e com os caroços de cereja. Os melhores resultados relacionam-se com a almofada com os caroços de cereja, apresentando uma atenuação da intensidade de $24,1 \mathrm{~dB}$ relativamente ao som de referência, enquanto se obteve uma atenuação de $8,8 \mathrm{~dB}$ relativamente ao som no interior da almofada de esponja. Conclusão: A almofada criada é um dispositivo de fácil utilização, ecológico e que pode ser aplicado em todos os pacientes com queixas de zumbido noturno.
\end{abstract}

Palavras-chave: Zumbido, audiologia, engenharia, dispositivo, almofada.

\section{INTRODUÇÃO}

O zumbido é um ruído diversificado que pode ser sentido, quer nos ouvidos, quer na cabeça, na ausência de uma fonte sonora externa (Jastreboff \& Jastreboff, 2000). É uma das queixas mais frequentes em adultos, sendo a sua prevalência entre $6,6 \% \mathrm{e}$ $18,9 \%$, aumentando para $30 \%$ em indivíduos com idade superior a 55 anos (Kim et al., 2015).

Cerca de $75 \%$ das pessoas que têm zumbido não se sentem desconfortáveis com ele. Contudo, existem situações nas quais a atividade neuronal relacionada com o zumbido provoca a ativação inadequada do sistema nervoso límbico e do sistema nervoso autónomo (SNA), aumentando o stress, a ansiedade e o foco no zumbido (Jastreboff \& Jastreboff, 2000).

O zumbido pode, ainda, estar associado a hiperacusia (intolerância a sons, mesmo de moderada intensidade), phonofobia (medo de alguns sons, normalmente, associados a experiências negativas) ou misofonia (forte aversão a certos sons). Na hiperacusia ocorre um aumento anormal da atividade neuronal, evocada por um som na via auditiva e que sofre uma ativação secundária do sistema límbico (Gonçalves et al., 2007). Na phonofobia, o sistema auditivo funciona normalmente, mas há uma reação intensa anormal do sistema límbico e do SNA, mesmo que a ativação do sistema auditivo ocorra a um nível relativamente baixo. Na misofonia, existe uma hiperconectividade entre a via auditiva, o sistema límbico e o córtex pré-frontal (área da atenção).

Para um bom diagnóstico é importante obter o máximo de informação clínica do paciente: história clínica, exames audiológicos, tais como audiograma tonal e vocal, avaliação do limiar de desconforto (UCL), acufenometria que determina a intensidade e frequência do zumbido (Crummer \& Hassan, 2004), impedancimetria (Esmaili \& Renton, 2018). As otoemissões acústicas por produtos de distorção (OEAPD) são também importantes, uma vez que fornecem informações úteis acerca da integridade estrutural da cóclea, principalmente ao nível do funcionamento das células ciliadas externas (Gentil et al., 2015). Exames de tomografia computorizada e/ou ressonância magnética à cabeça e pescoço podem também ser úteis no diagnóstico (Weissman \& Hirsch, 2000). Exames mais específicos são recomendados para despistar suspeita de outras patologias associadas (Schleuning, 1991).

A nível de tratamento, as principais técnicas prendem-se com o recurso à terapia sonora e à terapia cognitivo-comportamental (Esmaili \& Renton, 2018).

A terapia sonora pode ser utilizada isoladamente, através de geradores sonoros ou associada ao uso de próteses auditivas em 
caso de perda auditiva (Esmaili \& Renton, 2018).

Jastreboff \& Jastreboff (2000) defende a utilização do Tinnitus Retraining Therapy (TRT) que associa o aconselhamento com a terapia sonora. A TRT baseia-se no modelo neurofisiológico de Jastreboff e o objetivo é induzir a habituação e diminuir a perceção do zumbido, possibilitando aos pacientes um maior controlo sobre o seu zumbido. A TRT não tem implicações auditivas nem efeitos colaterais e pode ser aplicada em todos os pacientes com queixas de zumbido e/ou hiperacusia, uma vez que a habituação do sistema nervoso ocorre acima da origem do zumbido (Jastreboff, 2019).

Na habituação, é importante descobrir o momento a partir do qual o zumbido deixa de ser percetível quando é apresentado o som gerador (Fig. 1). O mixing point é o ponto no qual a intensidade do ruído gerador começa a alterar a perceção do zumbido sem o "eliminar" completamente. Por outro lado, a habituação provoca uma diminuição da força da atividade neuronal relacionada com o zumbido, quer no sistema auditivo, quer no trajeto do sistema auditivo para o sistema límbico e SNA.

A terapia cognitivo-comportamental foi desenvolvida

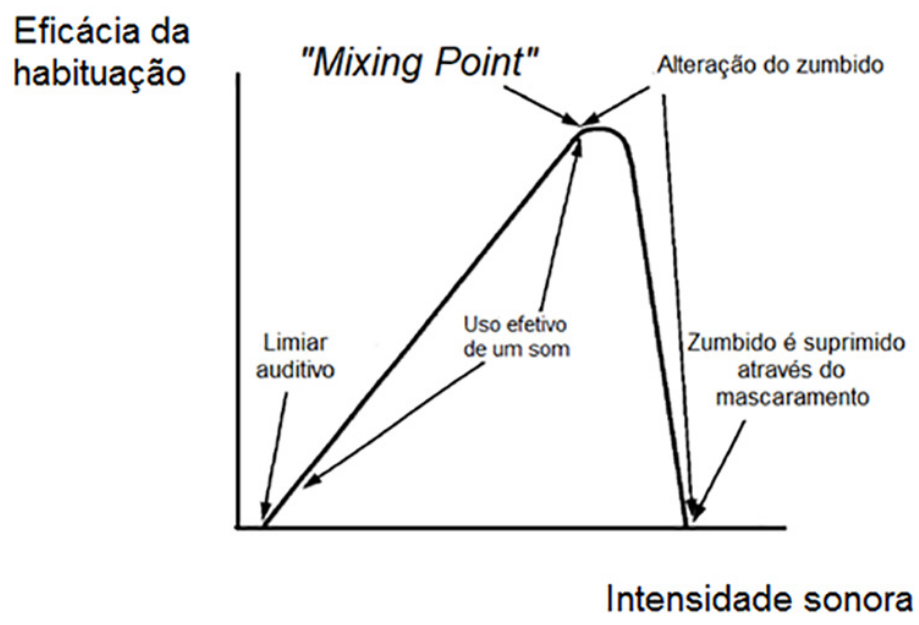

Figura 1: Esquema representativo do mixing point, adaptado pelas autoras (Jastreboff \& Jastreboff, 2000).

para tratar a ansiedade e a depressão, mas acredita-se que seja também eficaz no tratamento do zumbido (Tunkel et al., 2014). O objetivo é permitir ao paciente refletir sobre os seus pensamentos que resultam em angústia/ negatividade e incentivá-lo a adquirir a capacidade de reestruturar esses pensamentos para gerar positividade (Esmaili \& Renton, 2018).

\section{OBJETIVOS}

O zumbido é um processo que desencadeia ansiedade, distúrbios do sono, bem como uma série de problemas somáticos. Hoje em dia, o tratamento do zumbido é ainda um grande desafio para audiologistas, bem como otorrinolaringologistas. As lacunas existentes no conhecimento da sua fisiopatologia fazem com que os vários tipos de tratamentos tenham resultados muito irregulares. Na tentativa de melhorar a qualidade de vida destes indivíduos, surgiu a ideia de criar algo novo, que os auxiliasse em ambientes de descanso, nos quais a dificuldade em se abstrair do zumbido aumenta substancialmente.

Pretende-se com este trabalho desenvolver um dispositivo inserido numa almofada que consiga colmatar este problema e que possa ser utilizado em contexto real. $O$ equipamento permite a adaptação aos gostos sonoros de cada paciente, de forma a incentivá-lo a aderir ao tratamento e possibilitar um melhor prognóstico.

O objetivo passa também por criar uma solução confortável e acusticamente eficaz para o contexto pretendido, quer para o paciente com zumbido, quer para o parceiro que possa, eventualmente, partilhar o mesmo espaço de descanso.

\section{MATERIAIS E MÉTODOS}

Foi desenvolvido um dispositivo, introduzido no interior de uma almofada, com o objetivo de servir de apoio a pacientes com zumbido(Fig.2).Odispositivoécompostoporummicroprocessador, amplificador, altifalantes, entre outros componentes (Fig. 3). O Arduino UNO é uma placa microcontroladora programável de código aberto, que permite a construção de dispositivos digitais (McRoberts, 2015). A linguagem de programação mais comum é o Arduino IDE (Integrated Development Environment), que recorre a uma versão simplificada de C++ (Arduino, 2015). Neste projeto, foram utilizadas algumas bibliotecas do Arduino, incluindo "SD.h", "SPI.h", “TRMpcm.h" (que incorpora“"pcmRF.h").

A base de dados é constituída por faixas sonoras que foram uniformizadas, do tipo wav (Waveform Audio File Format) com 8 bits, a $16 \mathrm{kHz}$ e além disso foram convertidas para utilização em sistemas Mono. Foram utilizados diversos sons: tons puros $(250 \mathrm{~Hz}$ $1 \mathrm{kHz}$ e $4 \mathrm{kHz}$ ); tons complexos (ruído rosa, ruído branco) e músicas zen que têm como objetivo promover o relaxamento (pássaros na floresta, chuva na selva, som do mar com música eletrónica de fundo, água do riacho, grilos a cantar, mar agitado e orla da praia). O cartão SD removível permite ao audiologista selecionar previamente o conjunto de faixas sonoras mais adequadas a cada paciente. Do ponto de vista do utilizador, o paciente consegue facilmente reproduzir os diversos sons introduzidos.

O equipamento é completamente autónomo, uma vez que o dispositivo é alimentado por uma pilha de $9 \mathrm{~V}$.

O dispositivo foi totalmente introduzido no interior de uma almofada, o que possibilita a sua utilização em contexto real. Para enchimento da almofada, foram testados vários materiais, entre eles a esponja com alguns orifícios e os caroços de cereja, de modoa 
avaliar a melhor solução acústica, bem como a que proporcionasse maior conforto ao paciente. Estes factos foram suportados através da medição da intensidade sonora do altifalante no exterior das almofadas, representando a referência (Refa), e do altifalante no interior de cada almofada. Para monitorização desta avaliação foi utilizado um sonómetro CESVA Acoustic Instruments modelo SC- 30, em que os dados obtidos foram transferidos e analisados através do Software CESVA Capture Studio.

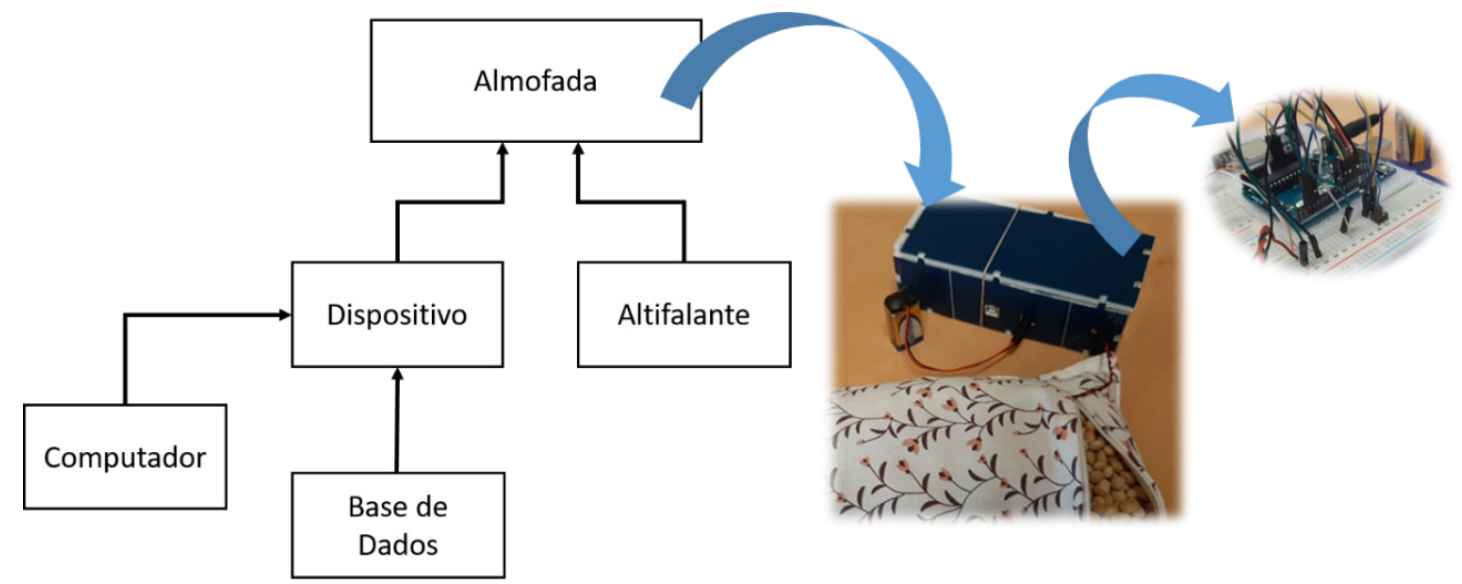

Figura 2: Esquema geral do funcionamento da almofada.

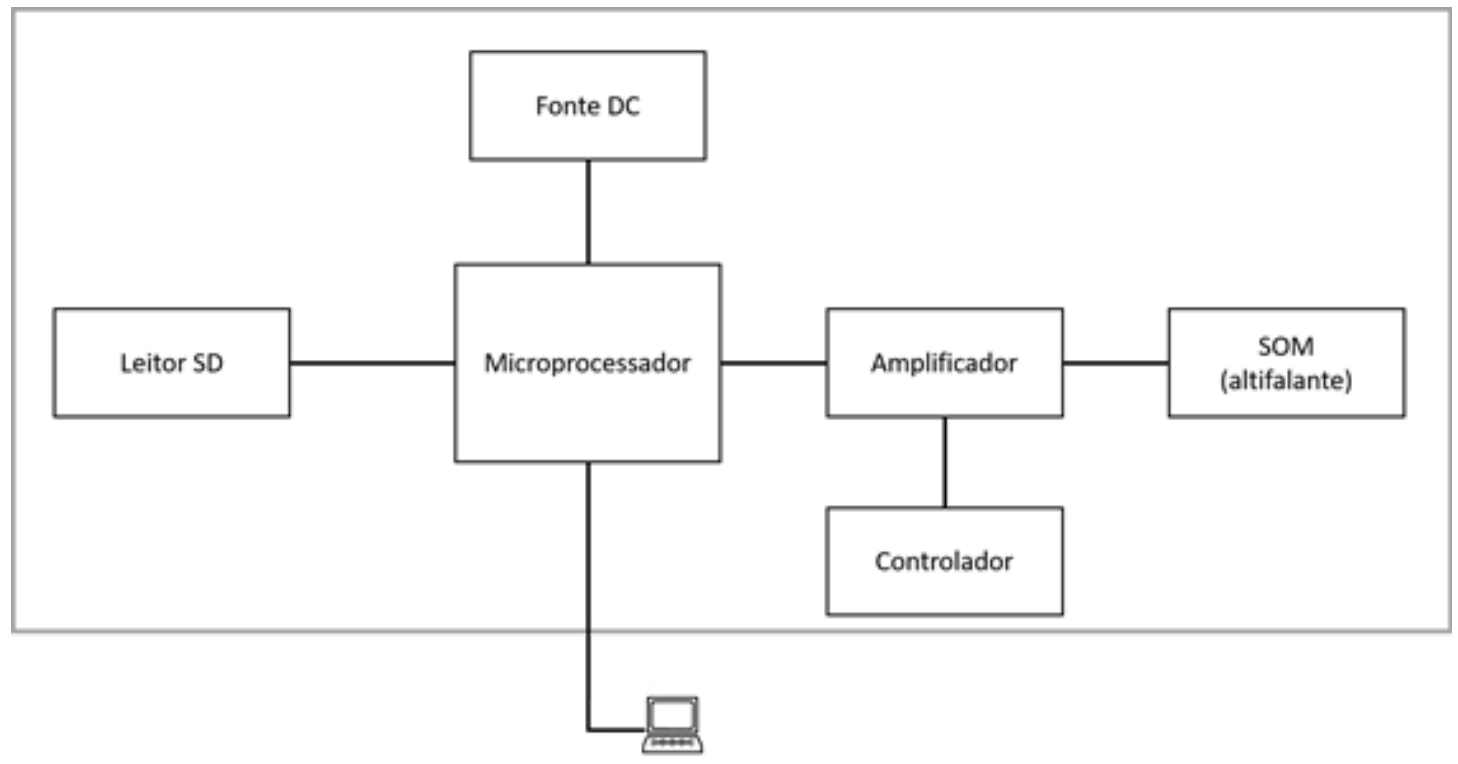

Figura 3: Componentes do dispositivo eletrónico.

Foi registada a intensidade durante $7 \mathrm{~s}$, nas mesmas condições e para 2 sons diferentes: tom puro de $4 \mathrm{kHz}$ e uma faixa musical. Para cada faixa sonora, foram testados os valores de intensidade com o altifalante no exterior e no interior de cada almofada. Sem alterar a mesma intensidade inicial foi avaliada a emissão sonora do altifalante, às mesmas distâncias do sonómetro: a $0 \mathrm{~cm}$ (encostado), $8,5 \mathrm{~cm}, 17 \mathrm{~cm}$ e $25,5 \mathrm{~cm}$, sucessivamente. Foi considerada como intensidade de referência a intensidade emitida pelo altifalante no exterior das almofadas e às mesmas distâncias do sonómetro, referenciadas anteriormente.

Apesar de ainda não ter sido aplicada na prática clínica, a almofada está ainda inserida num protocolo que inclui a aplicação do questionário THI (Tinnitus Handicap Inventory; Schmidt et al., 2006) e que é destinado a pacientes com zumbido persistente associado ou não a perda auditiva. O tratamento proposto ao paciente é baseado na análise das respostas a esse questionário.

Se o paciente apresentar dificuldades em se abstrair do zumbido durante o dia, é-lhe proposta a utilização de uma das app open-source reconhecidas internacionalmente e destinadas a esse efeito, nomeadamente "ZEN Tinnitus", criada pela Widex ou "Relief", desenvolvida pela ReSound GN.

Se, por outro lado, as dificuldades na abstração do zumbido forem essencialmente durante os períodos de descanso/ sono, nos quais o ambiente seja silencioso, é recomendado o uso da almofada. Para monitorizar a efetividade do tratamento, é aconselhável que o paciente realize novamente o questionário 30 dias após.

Em ambas as situações, recomenda-se a realização de atividades de relaxamento como o yoga, a acupuntura, a prática de exercício físico, de forma consciente e regular.

\section{RESULTADOS}

Para obtenção dos resultados, foram avaliadas as intensidades (de uma faixa musical e de um tom puro de $4 \mathrm{kHz}$ ) 


\section{Artigos Científicos}

em três condições distintas: emitidas pelo altifalante no exterior das almofadas e no interior de duas almofadas diferentes, uma de esponja e outra com caroços de cereja. Através da utilização do sonómetro CESVA Acoustic Instruments modelo SC-30, foi testado o comportamento da intensidade com a variação das seguintes distâncias do sonómetro: $0 \mathrm{~cm}$ (encostado), $8,5 \mathrm{~cm}, 17 \mathrm{~cm}$ e $25,5 \mathrm{~cm}$, sucessivamente. Utilizou-se o software CESVA Capture Studio para fazer a transferência dos valores da intensidade durante os $7 \mathrm{~s}$ de teste e, posteriormente, recorreu-se ao software Microsoft Excel para proceder ao tratamento dos dados obtidos.

Ao analisar os dados obtidos na faixa musical selecionada, percebeu-se que não seria possível efetuar uma avaliação correta, uma vez que o som apresenta inúmeras variações de frequência, intensidade e melodia e é difícil testar a mesma porção de $7 \mathrm{~s} \mathrm{em}$ todas as condições. Desta forma, optou-se por apresentar apenas os valores obtidos no tom puro de $4 \mathrm{kHz}$ (frequência e intensidade constante), por apresentar um espetro constante ao longo do tempo (Fig. 4).

Quando se recorre à almofada de esponja com alguns orifícios, a intensidade do tom puro diminui abruptamente, à medida que o sonómetro se distancia da fonte sonora (Fig. 5).

Por outro lado, na almofada com caroços de cereja, a intensidade do tom puro é menor de uma forma geral quando comparado com a almofada de esponja; no entanto, a diminuição da intensidade é mais gradual à medida que se afasta a fonte sonora do sonómetro. Para além disso, observa-se que para distâncias de $17 \mathrm{~cm}$ e $25,5 \mathrm{~cm}$, a intensidade emitida é menor quando o altifalante se encontra no interior desta almofada,

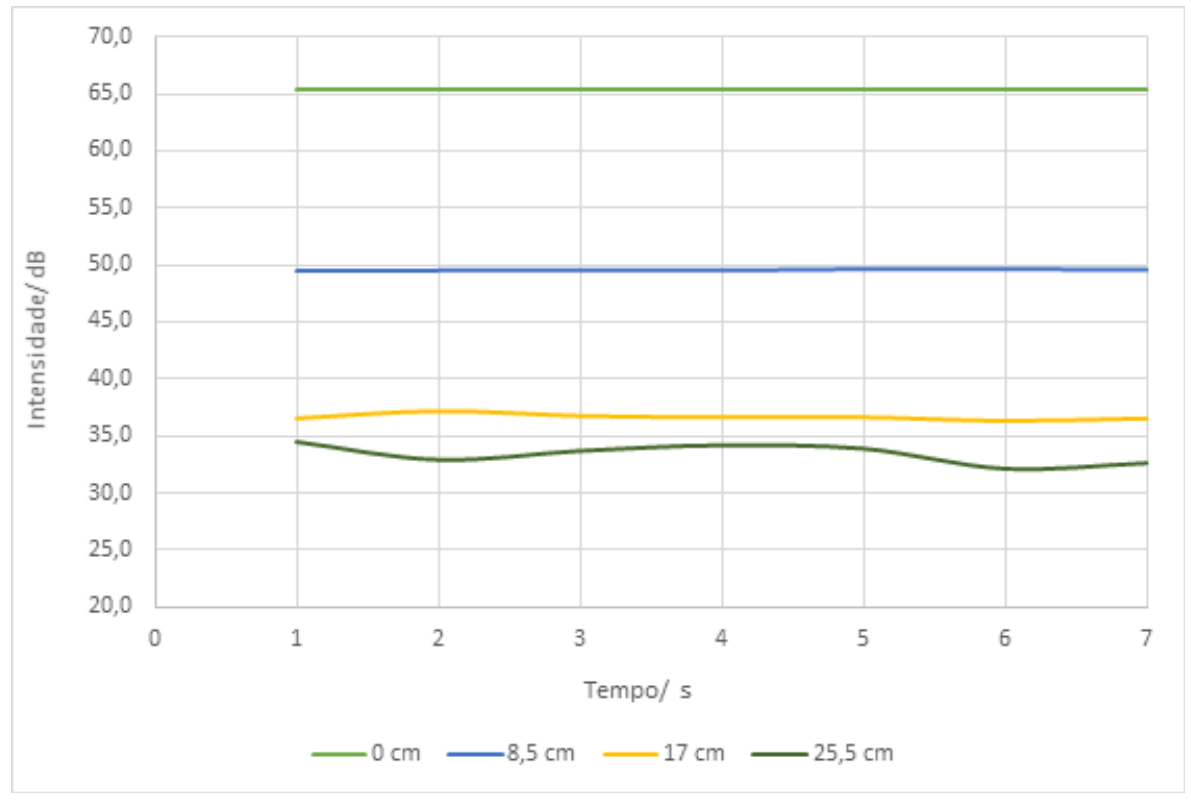

Figura 4: Alteração da intensidade de referência do tom puro de $4 \mathrm{kHz}$, no exterior da almofada, à medida que se afasta do sonómetro.

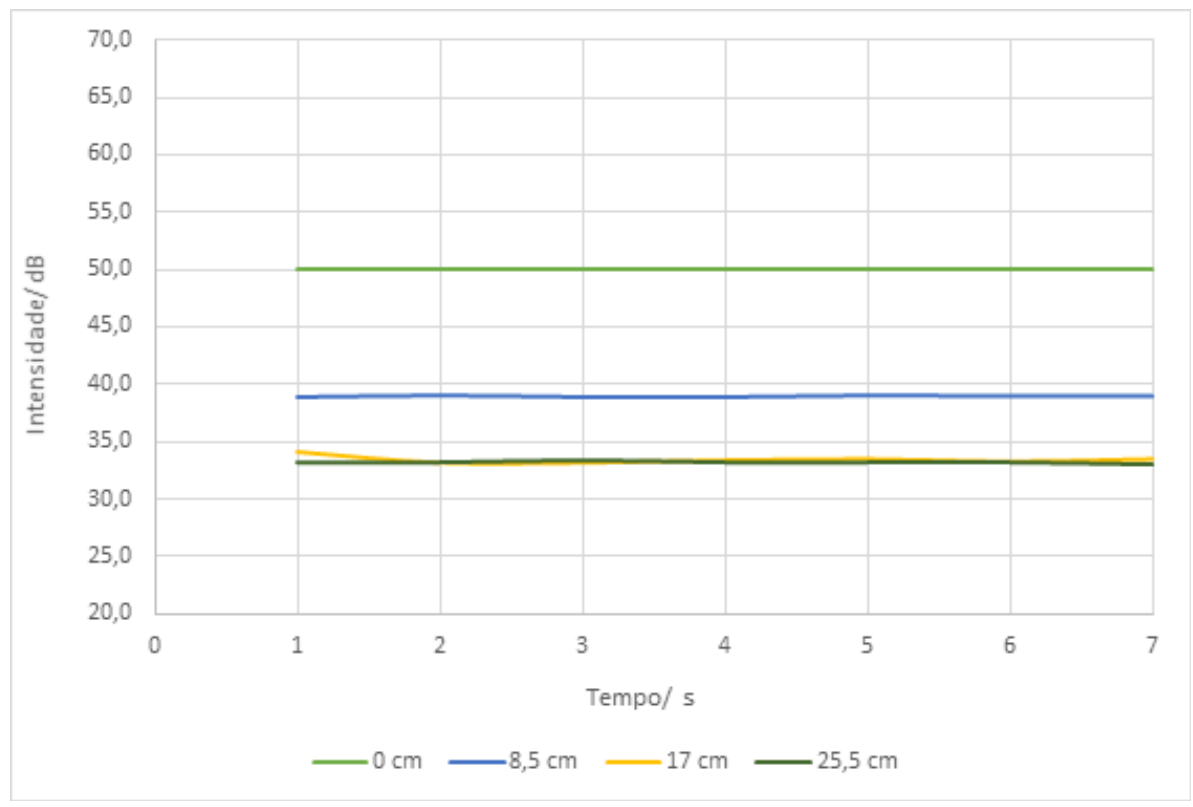

Figura 5: Alteração da intensidade do tom puro de $4 \mathrm{kHz}$, no interior da almofada de esponja, à medida que se afasta do sonómetro. 
apresentando valores em torno dos $30 \mathrm{~dB}$ e $23 \mathrm{~dB}$, respetivamente (Fig. 6).

Quando se coloca o sonómetro encostado à fonte sonora $(0 \mathrm{~cm})$, a intensidade avaliada como referência é de $65,4 \mathrm{~dB}$ - que obviamente corresponde à intensidade mais elevada comparativamente a qualquer uma das restantes situações (50,1 dB na esponja e 41,3 dB nos caroços de cereja), uma vez que o som se propagava sem obstáculos. No entanto, para uma distância de $25,5 \mathrm{~cm}$ do sonómetro, a intensidade de referência $(33,4 \mathrm{~dB})$ é semelhante àquela quando se introduz o altifalante dentro da almofada de esponja à mesma distância $(33,2 \mathrm{~dB})$, o que significa que o som se dispersa de forma similar para esses valores de distância. Por outro lado, na almofada de esponja verifica-se uma maior estabilização da intensidade a partir de determinados valores de distância. Já na almofada com caroços de cereja o mesmo não se observa. Por exemplo, quando o altifalante da almofada com caroços de cereja se encontra a $25,5 \mathrm{~cm}$ do sonómetro, a intensidade é de $22,8 \mathrm{~dB}$, ou seja, é inferior às situações anteriores nas mesmas condições. Nesta almofada, a intensidade apresenta sempre um comportamento decrescente à medida que o sonómetro se afasta da fonte sonora (Fig. 7).

\section{DISCUSSÃO}

No caso da almofada de esponja, o som é pouco nítido; no entanto, apresenta uma maior intensidade $(50,1 \mathrm{~dB}$, a $0 \mathrm{~cm})$ quando comparado com o altifalante no interior da almofada com os caroços de cereja $(41,3 \mathrm{~dB}, \mathrm{a} 0 \mathrm{~cm})$. Apesar da intensidade mais

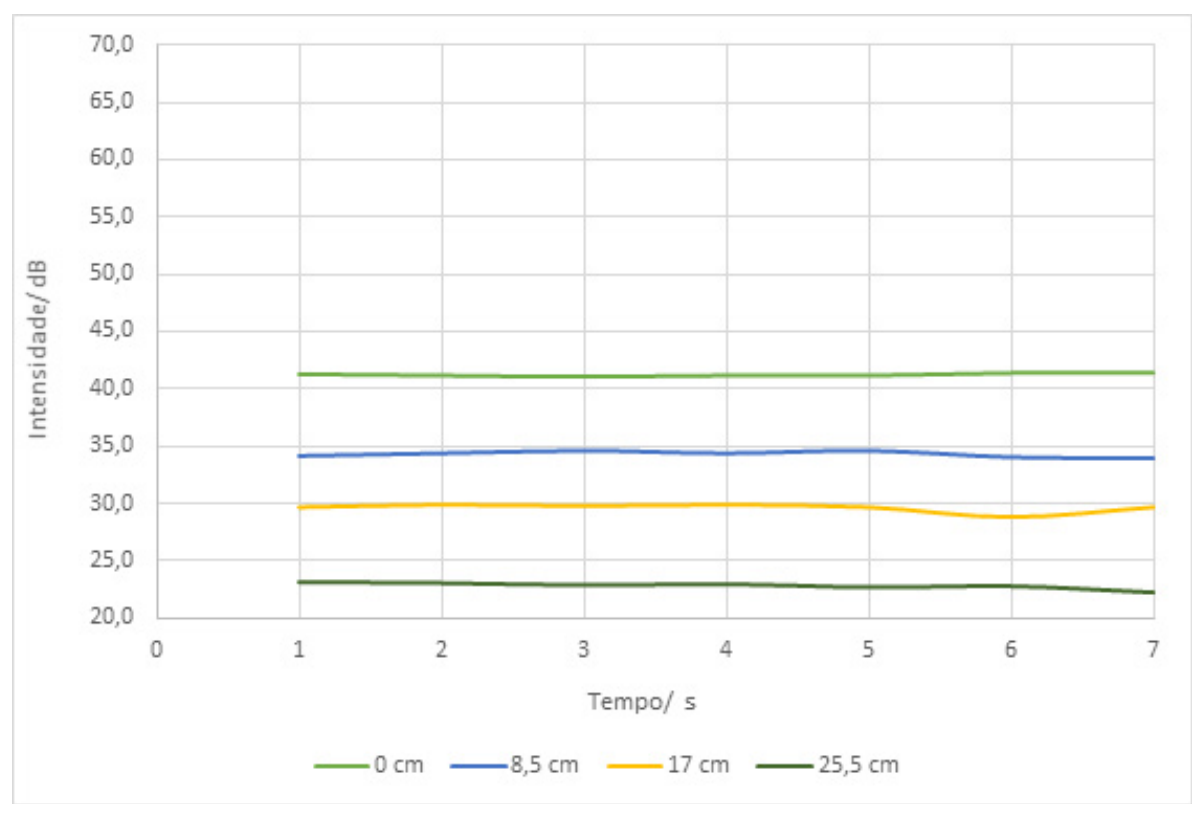

Figura 6: Alteração da intensidade do tom puro de $4 \mathrm{kHz}$, no interior da almofada com caroços de cereja, à medida que se afasta do sonómetro.

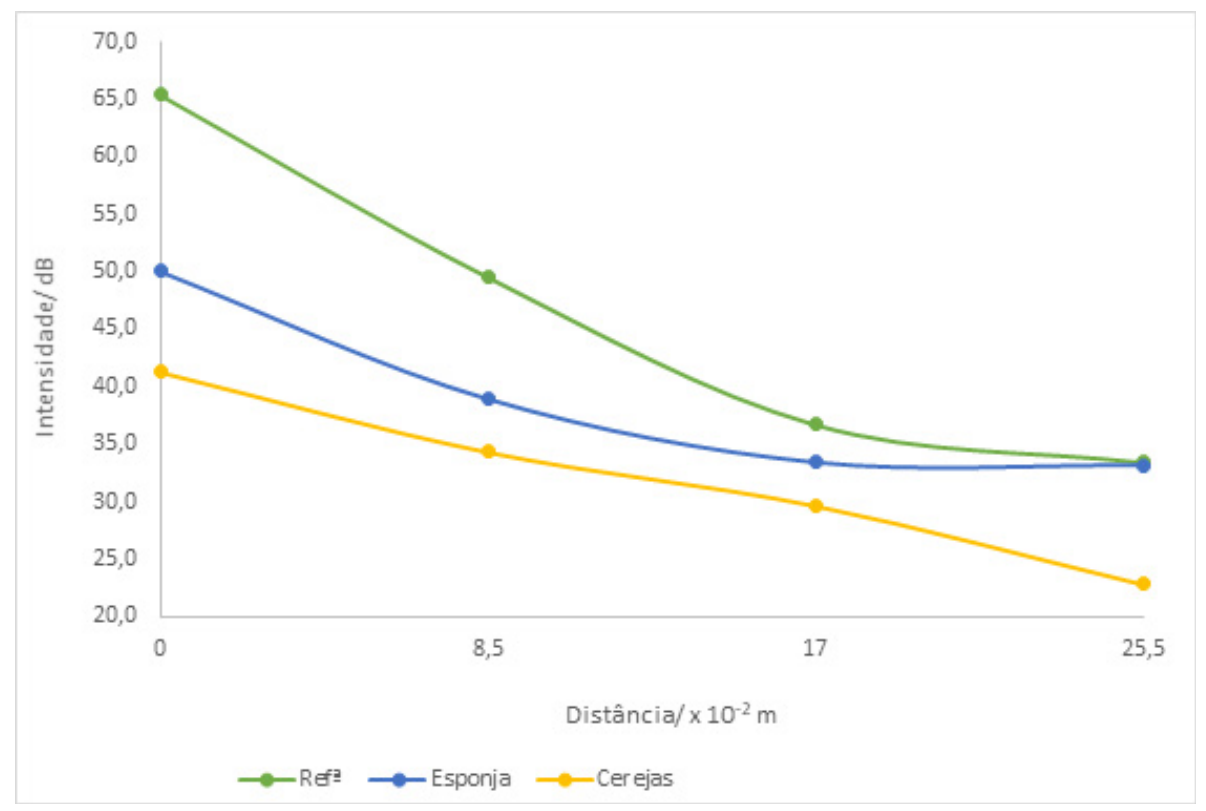

Figura 7: Comportamento da intensidade em função da distância da fonte sonora e do meio de propagação da onda sonora. 
reduzida neste último material, o som é mais claro, uma vez que a propagação do som nos sólidos é mais eficaz. O facto de existir espaços intersticiais impede que o som se propague para o meio ambiente, ficando assim mais restrito ao utilizador da almofada, razão pela qual a intensidade diminui sempre à medida que se afasta da fonte sonora. Este facto é importante em situações em que o indivíduo com zumbido que utiliza a almofada partilha a mesma divisão de descanso com alguém. À medida que a distância entre a almofada e o parceiro aumenta, a intensidade percecionada por este último diminuiu mais rapidamente, reduzindo assim o seu incómodo.

Foi testada a propagação de um tom puro em dois materiais diferentes, fazendo variar a sua distância à fonte sonora. Atendendo ao objetivo da almofada, os dados obtidos nesta experiência, permitiram excluir a esponja e optar pelos caroços de cereja como material preferencial para o enchimento da almofada. Apesar disso, seria relevante e enriquecedor para este projeto proceder à avaliação com outro tipo de materiais e, eventualmente, aumentar o tempo de teste.

A ideia desde projeto surgiu num contexto de diagnóstico audiológico, uma vez que a maioria dos pacientes apresenta dificuldades em se abstrair do seu zumbido no silêncio. É uma ideia inovadora na área da Audiologia que deveria ser aprofundada, quer em termos acústicos e eletrónicos, quer em termos de implementação no Mercado.

Sugere-se alguns melhoramentos, nomeadamente na capacidade energética assim como na incorporação de um temporizador de ciclos, de modo a aumentar o seu despenho. Recomenda-se ainda a melhoria da qualidade sonora emitida para evitar a distorção. Seria também conveniente substituir alguns componentes por material resistente às quedas e ao movimento da cabeça para evitar algum mau contacto que possa existir e possa comprometer o seu correto funcionamento. Atendendo à crescente "dependência" dos recursos tecnológicos, seria interessante incluir na almofada uma ligação por Bluetooth que permitisse o controlo remoto, através do smartphone.

Para finalizar, seria conveniente testar a almofada em casos clínicos reais para comprovar, efetivamente, a sua eficácia no "tratamento" do zumbido.

\section{CONCLUSÃO}

O protocolo desenvolvido é uma ideia inovadora que pretende melhorar a qualidade de vida de pacientes com dificuldade em se abstrair do seu zumbido durante o período de descanso. A nível audiológico, o dispositivo criado deve ser utilizado de forma a trabalhar a nível do loop inferior, ou seja, a nível do subconsciente. Neste ponto, a habituação do zumbido é mais eficaz.

Além de ser fundamental a aplicação do tratamento mais correto, é essencial que o próprio paciente seja capaz de adquirir estratégias de coping, de forma a conseguir lidar com a sua situação clínica. Atendendo ao aumento da preocupação com a qualidade de vida dos pacientes, o protocolo deve ser aplicado a todo o tipo de pessoas com queixas de zumbido, independentemente da sua origem (coclear ou central), da faixa etária do indivíduo, do sexo ou classe social.

O dispositivo criado foi introduzido totalmente dentro da almofada e permite que seja utilizado em qualquer lugar sem o perigo de asfixia. É cómodo, fácil de transportar e de utilizar por qualquer indivíduo.

O uso dos caroços de cereja foi a alternativa encontrada que possuiu uma melhor propagação da onda sonora no contexto pretendido. Além disso, este material é amplamente utilizado no relaxamento muscular, o que pode ser uma mais-valia atendendo às evidências, já abordadas, de que o zumbido está muitas vezes relacionado com stress. Por ser um material orgânico, tem ainda vantagens a nível da gestão de recursos, uma vez que se trata de um material reutilizável, fácil de higienizar, ecológico e amigo do ambiente.

\section{CONFLITO DE INTERESSES E FINANCIAMENTO}

Este projeto foi desenvolvido no âmbito da Tese de Mestrado em Engenharia da Computação e Instrumentação Médica, no ISEP, sem a atribuição de bolsas de financiamentos. É de ressalvar que não existe conflito de interesses com esta Instituição.

Para além disso, há algumas marcas que trabalham no Mercado, na área da Audiologia inclusive, e que foram referidas ao longo deste artigo; no entanto, também não existem quaisquer conflitos de interesses com as mesmas.

\section{REFERÊNCIAS BIBLIOGRÁFICAS}

Arduino, S. A. (2015). Arduino. Arduino LLC.

Crummer, R. W., \& Hassan, G., Diagnostic approach to tinnitus. American family physician, 69(1), 120-126, 2004.

Davis, P., Paki, B., \& Hanley, P., Neuromonics Tinnitus Treatment: Third Clinical Trial. Ear and hearing, 28, 242-259, 2007. doi:10.1097/ AUD.0b013e3180312619

Esmaili, A. A., \& Renton, J., A review of tinnitus. Aust J Gen Pract, 47(4), 205, 2018.

Gentil, F. et al., Comparison of otoacoustic emissions in patients with tinnitus having normal hearing versus mild hearing loss. Int Tinnitus J, 19(2), 39-46, 2015. doi:10.5935/0946-5448.20150007

Gonçalves, M. S., Tochetto, T. M., \& Gambini, C., Hiperacusia em músicos de banda militar Hyperacusis in military band musicians. Rev Soc Bras Fonoaudiol, 12(4), 298-303, 2007.

Gulya, A. J., Evaluation of tinnitus. Primary care medicine: office evaluation and management of the adult patient. 4th ed. Philadelphia: Lippincott Williams \& Wilkins, 1123-1125, 2000.

Jastreboff, P. J., \& Jastreboff, M. M., Tinnitus retraining therapy (TRT) as a method for treatment of tinnitus and hyperacusis patients. $J$ Am Acad Audiol, 11(3), 162-177, 2000.

Kim, H.-J. et al., Analysis of the prevalence and associated risk factors of tinnitus in adults. PLoS One, 10(5), e0127578, 2015.

McRoberts, M., Arduino básico. Novatec Editora, 2aed, 2015.

Schleuning, A. J., Management of the patient with tinnitus. The Medical clinics of North America, 75(6), 1225-1237, 1991.

Schmidt, L. P. et al., Adaptação para língua portuguesa do questionário Tinnitus Handicap Inventory: validade e reprodutibilidade. Rev. Bras. Otorrinolaringol., 72, 808-810, 2006.

Sindhusake, D., et al., Prevalence and characteristics of tinnitus in older adults: the Blue Mountains Hearing Study: Prevalencia y características del acúfeno en adultos mayores: el Estudio de Audición Blue Mountains. International journal of audiology, 42(5), 289-294, 2003.

Tunkel, D. E., et al., Clinical practice guideline: tinnitus. Otolaryngol Head NeckSurg, 151(2Suppl),S1-s40,2014.doi:10.1177/0194599814545325

Weissman, J. L., \& Hirsch, B. E., Imaging of tinnitus: a review. Radiology, 216(2), 342-349, 2000 